Portland State University

PDXScholar

$5-1-1969$

\title{
An examination of disengagement among elderly people in a low income public housing facility
}

\author{
Linda Bennion \\ Portland State University \\ Marion Paradis \\ Sheila Petrie
}

Follow this and additional works at: https://pdxscholar.library.pdx.edu/open_access_etds

\section{Let us know how access to this document benefits you.}

\section{Recommended Citation}

Bennion, Linda; Paradis, Marion; and Petrie, Sheila, "An examination of disengagement among elderly people in a low income public housing facility" (1969). Dissertations and Theses. Paper 915. https://doi.org/10.15760/etd.915

This Thesis is brought to you for free and open access. It has been accepted for inclusion in Dissertations and Theses by an authorized administrator of PDXScholar. Please contact us if we can make this document more accessible: pdxscholar@pdx.edu. 
AN ABSTRACT OF THE GROUP PROJECT OF Linda Bennion, Marion Paradis, and Sheila Petrie for the Master of Social Work presented May 7, 1969.

Title: An Examination of Disengagement Among Elderly People in a Low Income Public Housing Facility.

APPROVED BY MEMBERS OF THE GROUP PROJECT COMMITTEE:

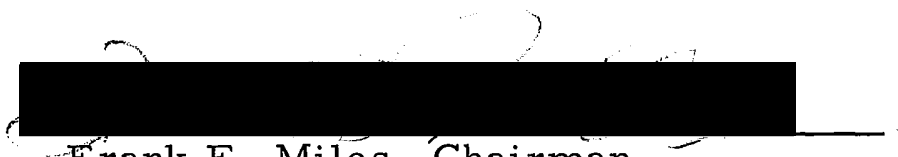

Frank F. Miles, Chairman
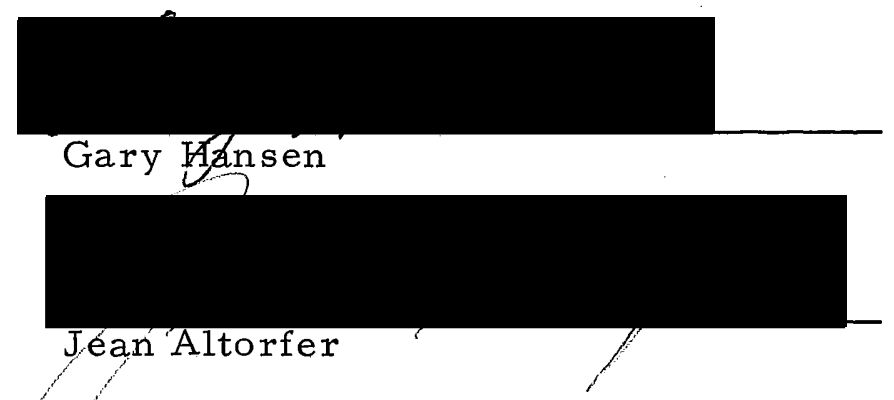

This project studied the consequences of disengagement among elderly people and examined the respondent's opinions about society's responsibility to the aged.

The study population was limited to 48 elderly people, equally divided between men and women, married and unmarried; residing in Northwest Tower, a high-rise public housing facility, The possible consequences of disengagement which were 
studied included isolation, depression, frustration, despair, factors preventing satisfaction with present circumstances, desired activities in relation to available activities, and energy and desire relative to activity and responsibility. Finally, opinions were sought about society's responsibility to the elderly.

Six general hypotheses guided the development of the study:

The older person experiences progressive disengagement from society resulting in feelings of isolation, depression, frustration, and despair;

the aging person is dissatisfied with the degree of this process of social disengagement;

the aging person gains satisfaction by participating in activities which lead to individual growth and/or benefit to others;

the aging person lacks capacity and/or desire to participate in many activities or to continue the full-time roles of parent, job holder, and citizen;

the aging person would like to choose his activities according to his desires and needs; and

the aging person will more likely participate in activities if he is able to obtain adequate health care and has financial security.

Descriptive and statistical inferential tests were used to analyze the data. A relatively small percentage of possible disengagement in the recreational, occupational, and family life areas occurred during the individual's life span from age 40 to age 70 . The percentage of possible disengagement in these areas increased dramatically in the life span from age 70 . 
Most of the respondents rejected loneliness and depression and felt in good spirits most of the time. A tendency toward less and less contact with others was seen.

Statistically significant differences were found between activities which were presently enjoyed, which were basically individual and passive in nature; and activities respondents would plan for themselves, which were of a significantly more social nature involving them in rewarding activity with others.

Statistically significant differences were found between interest in the activity program available at Northwest Tower, basically recreation and entertainment; and the activities respondents would include in their program, mainly designed for self-enhancement or benefit to others.

Statistically significant differences were also found between the number of activities available and the smaller number desired.

The findings suggested that the preponderance of the respondents desired to withdraw from major responsibilities outside their household. Of those who desired responsibilities such as occupation, family or civic, they were prevented from assuming them most of the time because of their increasing age, deteriorating health, and lack of money. These were also the main factors operant in restricting their activity and preventing them from enjoying satis:factory ways of living. 
The majority of opinions as to society's responsibility to the aging suggested that intervention was necessary to provide financial security, health care, and better and cheaper methods of transportation.

The findings of the study suggested the importance of more intensive research in planning programs directly related to meeting the individual needs of elderly people. 
AN EXAMINATION OF DISENGAGEMENT AMONG ELDERLY PEOPLE IN A LOW INCOME PUBLIC HOUSING FACILITY

by

LINDA BENNION

MARION PARADIS

SHEILA PETRIE

A group project submitted in partial fulfillment of the requirements for the degree of

MASTER OF SOCIAL WORK

Portland State University

1969 
TO THE OFFICE OF GRADUATE STUDIES:

The members of the Committee approve the group project of Linda Bennion, Marion Paradis, and Sheila Petrie presented May 7, 1969.

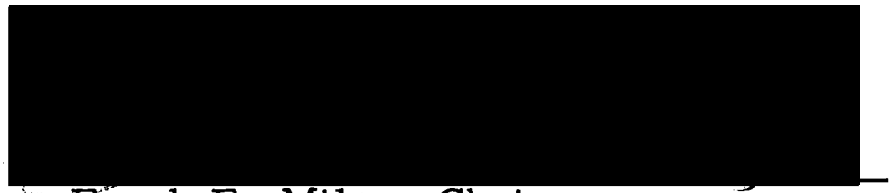

Frank F. Miles, Chairman

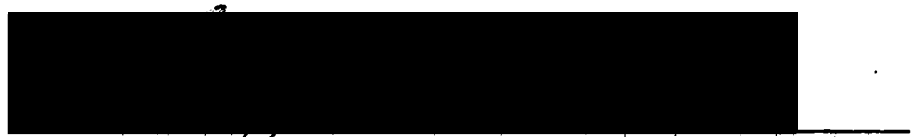

Gary Hansen

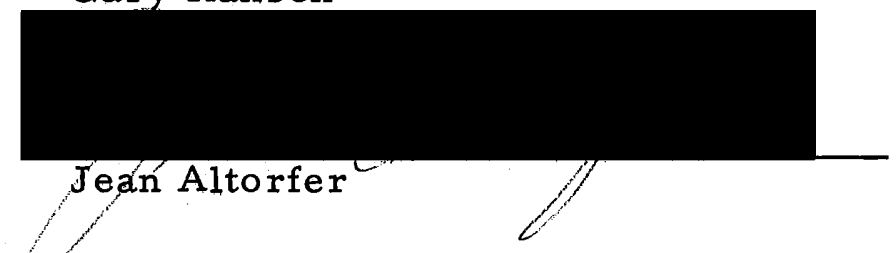

APPROVED:

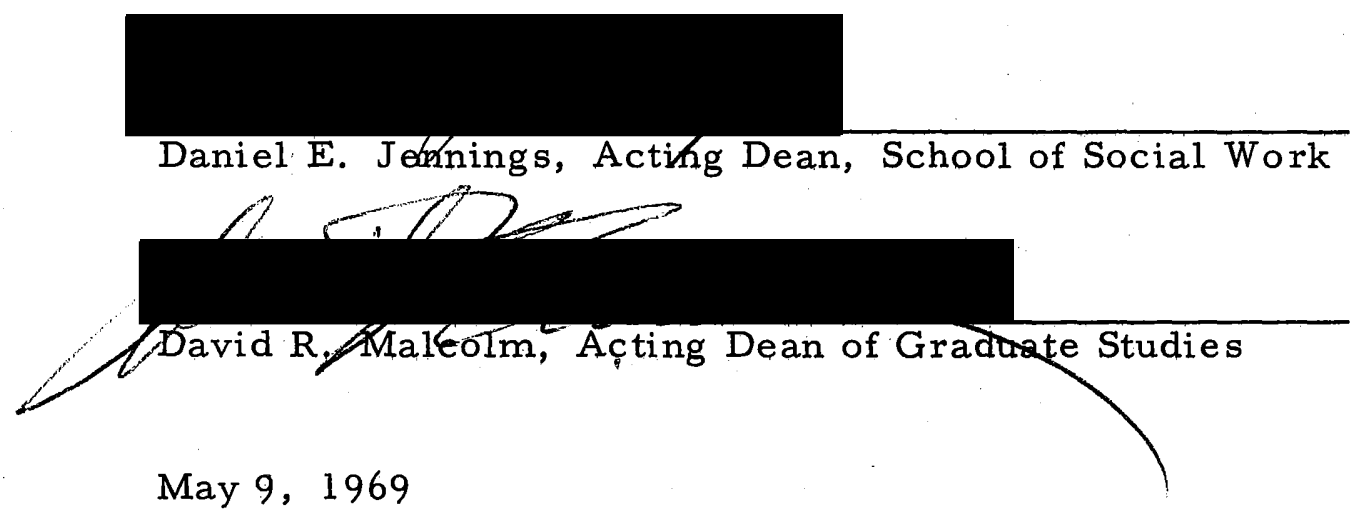




\section{ACKNOW LEDGEMENTS}

We wish to acknowledge with gratitude the assistance and materials provided to the group by the elderly residents of Northwest Tower participating in the study; Lorraine Thompson, Director of Northwest Tower; Ruth Brewer, Librarian, University of Oregon Department of Gerontology; and Walter Klopfer, Professor of Psychology, Portland State University. 
TABLE OF CONTENTS

PAGE

ACKNOW LEDGMENTS . . . . . . . . . . . . . . . . iii

LIST OF TABLES . . . . . . . . . . . . . . . . vi vi

CHAPTER

I THE PROBLEM ............... . . 1

Aims of the Project .......... 1

Some Characteristics of the Population. . 3

Description of Northwest Tower and

Their Program . . . . . . . . 3

Definitions .............. . . 5

Limitations............. . . 6

Importance to Social Work. . . . . . 7

Review of Selected Theory. . . . . . 9 9

II THE APPROACH ............. 18

The Sample.............. . . 20

The Schedule.............. . 21

Pretests and Training ........ . . 23

Collection of Data ........... . . 24

Tabulation .............. . . . 27 
III. FINDINGS AND IMPLICATIONS . . . . . . .

Findings . . . . . . . . . . . . . .

Disengagement

Isolation

Depression

Frustration

Despair

Dissatisfaction with Degree of

Disengagement

Attainment of Satisfaction

Desire for Many Activities

Desire and Capacity to Continue

Life-Time Responsibilities

Desire to Select Activities

Negative Aspects of Aging Which

Inhibit Participation in

Activities

Society's Responsibility

Summary of the Hypotheses and

Conclusions

Implications . . . . . . . . . . . . . . .

Critique. . . . . . . . . . . . . .

Suggestions for Further Research.... .

BIBLIOGRAPHY . . . . . . . . . . . . . . . . . . 


\section{LIST OF TABLES}

TABLE

PAGE

I Summary of Tests of Significance Between the

Actual and Theoretical Response Distri-

butions at .05 Level...........

II Percentage of Mpvement Toward More or Less

Activity in 48 People Ages 49 to 60 and 13

Ages 40 to $(72-88)$...........

III Distribution of Satisfaction Scores ......

IV Present Responsibilities............

V Additional Responsibilities.Desired . . . . .

VI Responsibilities from which Older People Would Like to Withdraw . . . . . . . . . .

VII Factors Preventing Respondents from Assuming

Additional Responsibilities . . . . . . .

VIII Factors Preventing Ideal Way of Life ......

IX Conditions which Make It Difficult to Participate in Activities . . . . . . . . . . . .

$\mathrm{X}$ Society's Responsibility to the Aging . . . . .

XI Research Hypotheses and Conclusions. . . . . 


\section{CHAPTER I}

\section{THE PROBLEM}

This is a study of 48 low income elderly people living in a high rise public housing facility of Portland, Oregon in 1968 with reference to their possible disengagement and dissatisfactions with their present role in life. The study attempts to discover what changes the elderly would like, what prevents them from making changes, and what society could do to help.

\section{AIMS OF THE PROJECT}

The project grew out of an expressed need of housing authority officials in Portland, Oregon for a more independent assessment of housing needs and activities for older people.

The approach was basically descriptive and was based on the hypothesis that the aging person and society participate in a disengagement process of mutual withdrawal. The aging person was initially seen as affected by: (1) internal and external bodily changes; (2) loss of status; (3) loss of significant people; (4) modification of

1 people with whom the respondent has an important and meaningful relationship such as spouse, close friends and/or relatives. 
range of available roles or activities; (5) nearness of death.

The original aims of the project were: (1) to determine whether the aging person does participate with society in a mutual withdrawal; (2) to determine whether the aging person desired to do something and to have society do something to prevent the withdrawal from happening; (3) to ascertain the present capabilities of the aging person to reverse the process of detachment from productive and satisfying roles; (4) to ascertain what contribution society could make to increase the capabilities of the aging person to assume more satisfying roles.

Four initial assumptions guided the group's approach to achieving these aims. The first assumption was that because of the process of disengagement and the resulting isolation, depression, frustration and despair, the aging person does little to alter his social roles. The second assumption was that the aging person is dissatisfied with this process of disengagement and mutual withdrawal and would like to assume a more satisfying and fulfilling role in society. The third assumption was that if society is willing to assume its responsibility in helping the aging person to assume a more satisfying and fulfilling role and provide the means by which he could do so, then the aging person is willing and capable of change and redirection. The fourth as sumption was that the aging person does not have the capacity or the desire to maintain his lifetime 
roles connected with raising a family, holding full-time job and bearing civic responsibilities; but he would like to choose his activities and responsibilities in relation to his energies and desires. The final, research hypotheses are outlined in the Approach chapter.

\section{SOME CHARACTERISTICS OF THE POPULATION}

The study population consisted of 12 unmarried males, 12 unmarried females, and 12 married couples. The individuals ranged in age from 62 to 88 with a mean age of 76.4 . In general, the respondents were compelled to use public transportation or to walk. Only five owned cars and only two others were able to request trans portation from their families. Thirty-three respondents classified themselves as belonging to a specific church. The denominations were varied but all were either Catholic or Protestant. Only one unmarried male belonged to a recreation club outside Northwest Tower.

III. DESCRIPTION OF NORTHWEST TOWER AND THEIR PROGRAM

The Housing Authority of Portland, Oregon owns and operates a number of low-rent projects serving families of modest incomes. Northwest Tower is one of these projects operated as a community service. 
Northwest Tower consists of two buildings with a total of 180 units. The hi-rise unit has 75 efficiency units and 75 one-bedroom units which have been specifically designed for elderly occupants. The three-story building consists of 27 two-bedroom units and 3 three-bedroom units for families with small children. This housing project, located at $335 \mathrm{~N}, \mathrm{~W} .19 \mathrm{th}$, is close to bus service and the downtown shopping area, and there are several churches in the vicinity.

Northwest Tower also has covered parking for 50 cars, a fenced play area for the children residing in the three-story building, and a two-story community center providing recreational and social activities for the residents.

Because federal and state laws prohibit competition with private rental and home-building industries, it is necessary that a family be within the income limits set by the Housing Authority and be in need of assistance to obtain adequate housing before eligibility can be established.

Rental charges amount to approximately one-fourth of the applicant's income. Heat, electricity, water, and garbage service are included in this rental charge. Further, Northwest Tower also furnishes ranges, refrigerators, and draperies.

This housing facility is in the center of a group of privately owned and operated apartment houses. Any elderly person, married 
or single, with maximum assets of $\$ 5,000$ or less and a maximum income on admission of $\$ 3,500$ per year is cligible to move into Northwest Tower. The assets counted do not include personal items such as automobiles, furniture, or clothing. Further, the income of the elderly person may increase 20 per cent while residing in the project before it becomes necessary for him to move.

The government requires that public facilities meet exacting physical specifications. The materials used to construct Northwest Tower were of high quality and durability. Expenses of material and construction, therefore, left little money for the purchase of decorating materials which would enhance the interior of the apartments. Nevertheless, because of their interest in their homes, the residents have done much to add warmth to their apartments.

\section{DEFINITIONS}

In establishing the hypotheses, certain words required clarification. These words were disengagement, isolation, despair, frustration, unmarried, and growth. In the formation of the hypotheses, the words were generally defined using the following terms:

Disengagement connotes lessened participation in the normal expected roles in the areas of family, recreation, and occupation;

Isolation connotes lack of human contact;

Despair means without hope;

Frustration symbolizes desired change that is blocked;

Unmarried connotes the marital status of the individual at the time the interview was held. 
Growth is learning and experiencing new things in the social, emotional, and physical life areas,

Operational definitions were the actual questions together with the respondent's reaction to each concept as recorded.

All other concepts in the hypotheses were defined according to common lay interpretation.

\section{LIMITATIONS}

Limits on time, number of project members, and the nature of the interview schedule necessitated reducing the size of the population studied to a manageable number. Any conclusions drawn from this study must be tempered by the knowledge that the population interviewed included only 12 unmarried males, 12 unmarried females, and 12 married couples.

The study was further limited by the ages of those interviewed. About 63 per cent were over 75 years of age --10 years beyond the usual retirement age.

This project was requested by the Portland Public Housing Authority to gain information about the attitudes and feelings of the older people who occupy public housing facilities. The study population was therefore limited to low income elderly people who reside in Northwest Tower (a public housing facility). 
Since gerontological research has been relatively neglected by the social work profession, it was not possible in this project to obtain definitive conclusions about the problems posed for the study. It was the feeling of the project members that this study should be confined to an exploration of the problem with the hope that future projects suggested by this study would be undertaken.

\section{IMPORTANCE TO SOCIAL WORK}

Gerontological research in social work has been a relatively neglected area. In reading the titles of several hundred Master's studies in seven Schools of Social Work, only two theses were found relating to the aged, and these were not directly related to the subject of the present study.

Several factors, however, have compelled the social work profession to take an increased interest in the problems of the aged. Coleman (4, p. 497) stated:

Through the prolongation of life by medical science, the United States is approaching a far greater older population, both absolutely and relatively, than any other country has ever had in all history, and we can expect this trend to continue. At mid-century, figures showed ten million people in the United States over sixty-five; in 1960, the number had increased to almost sixteen million. By 1980, it is expected to approximate twenty-five million--some ten per cent of the total population.

Another factor which has contributed to this increased interest is what is termed by Coleman (4, p. 499) as sociological aging. 
There is also what may be called sociological aging-changes in the position of the individual as a member of his family and of society. These changes typically include retirement from work, completed parental roles, death of a husband or wife, reduced income, and a considerable increase in leisure time. Concomitant with these are changes in the individual's self-concept and social role as well as in images, attitudes, and expectations which society expresses toward him. Some aspects of sociological aging have positive as well as negative values, but all require adjustment on the part of the individual. All too often the older person is not adequately prepared for later maturity and feels devaluated, alone, and alienated from the world about him.

Social workers have a responsibility to become aware of the problems of the aged and if necessary help them adjust to the process of aging.

Federal legislation such as Titles 18 and 19 of the Social Security Act and Title $\mathrm{V}$ of the Older Americans Act have increased the means by which the social work profession can become involved in understanding and helping solve the problems of their aged clients. It is important that social work researchers take every opportunity to add to the profession's body of knowledge about aging.

Social workers have a responsibility to acquaint themselves in the problems of the aging because of the beliefs inherent within the profession. According to Boehm (1, p. 36):

Social workers are concerned with meeting basic human needs in the social realm. This concern is viewed not as an end goal of social work, but rather as a means to an end. This position is based on the view that the satisfaction of basic human needs is an essential condition for the attainment of human dignity and constitutes a necessary basis for individual self-fulfillment, the goal of social work as well as of other 
professions. The expression of basic human needs and the content of living are culturally conditioned. They vary from society to society, from time to time, and within societies may vary from group to group.

. . Such a view of social need would lead to a concept of social work activities as ongoing and essential for the effective functioning of individuals and groups in society. This view also implies that social workers will shift their focus of professional activities to new needs as they arise from the ever faulty interaction between individuals and social institutions.

It is the nature of social work to participate in the identification and elimination of the gap that hampers the individual self-fulfillment. In the United States and Canada it can be assumed that it is primarily the complexity of social life and/or the coexistence of conflicting value systems which make it difficult for social institutions to keep pace with meeting existing as well as emerging social needs. In other cultural contexts, such as technologically underdeveloped areas, social needs may be the result of primarily deficient material resources.

\section{REVIEW OF SELECTED THEORY}

Initial impetus for the study was given by the group members' knowledge of the theory of disengagement $(5,6)$ and concern about its possible consequences. A survey of the literature revealed the existence of three other general theories relating to the process, results, and action toward the treatment of disengagement. Though every general theory tacitly accepts the notion that disengagement exists within the aging population, they offer different definitions of its nature, degree and consequences, and draw different conclusions as to possible courses of action. 
The Theory of Disengagement

One sample group of healthy adults with no major economic worries, ages 50 to 70 and a quasi-sample of very old people with relatively the same characteristics provided the background for Cumming's and Henry's (6) development of the theory of disengagement.

In accepting the observation that older people are less involved than when they were younger they suggested that there is a biological basis for the aging person's lessening of interest or involvement in his environment. Because the ultimate disengagement is death and because all people expect death, both society and the aging person prepare for it by gradual mutual withdrawal. The process of disengagement differs between men and women because each group has life roles peculiar to each sex. The approach, its intensity and degree, to disengagement also differs for each person because of his individual qualities and personality. Disengagement is universal because it is present in the aging people of every culture. However, the form it takes is determined by the culture within which it exists. Preoccupation with self results in less activity with others. As the person withdraws, he gradually loses his ability to interact with others. Disengagement thus becomes a cycle. Less interaction results in a loss of ability to interact and increases the person's desire to withdraw. 
At the outset, the theory was designed to describe the aging person's withdrawal without making any assumptions as to its desirability. A corollary to the theory suggests, however, that if different roles for the person who has abandoned his or her central life role are not available, a crisis or loss of morale will result.

Cumming (5) later modified her conception of the theory somewhat by suggesting that the variations in the process which were attributed to social pressures, especially between men and women, might also be related to the dissimilar temperaments of people. This dissimilarity might not only affect the degree and intensity of disengagement but could result in a vital difference in style. "Combining biological and social variables within the framework of the disengagement theory, it might be possible to suggest a wider variety of styles of interaction in old age than would otherwise be possible." (5, p. 379) Disengagement, however flexible, remained as apparent as before as an inevitable process.

Henry (10) modified his concept of the theory by first acknowledging that a positive factor of disengagement would be, that one could structure his time as he wished. Once objects and outer events lose their control of the individual, he alters his view of their importance. The fully-engaged man is bound, the disengaged man is free. Given resources and health enough to exercise this freedom, the ability to enjoy old age may be the ability and opportunity to use 
freedom. (7)

Henry (10) recognizes that sociail environmental events are not sufficient indices by which to predict the processes of disengagement since they also appear to relate to the various types of personality processes. The challenge is not to construct or adopt theories relating to the processes of disengagement but to deal with the data directly in terms of program planning to enable the older person to use his new freedom.

Parsons (14) gives a different direction to the process of disengagement suggesting that since American society spends much of its time preparing for the future, old age should be its consummatory phase when the individual harvests the fruits of his life's labor. The pattern of the last years of life should be seen as a reward for a life well-lived.

The disengagement theory signified a major departure from then current thought regarding aging. The controversy generated by its publication produced much new research and study and resulted in the development of new concepts and the expansion of pre-existing thought.

The Intrinsic or Activity Theory of Disengagement

As a counterbalance to the functionalist theory of disengagement 
which seems to relegate ${ }^{2}$ the older persons to disengagement, the interactionists point out that older people need engagement $(12,13,16)$ and that those who remain engaged express greatest satisfaction with their lives. (9)

The interactionists do not question the older person's tendency to disengage:

Regardless of precisely at what age they begin to think of themselves as elderly, for most Americans there tends to be a marked change in self-conception. This includes a shift in thinking of oneself; as progressively physically and mentally handicapped, from independent to dependent, and from aspiring to declining. Because most of the changes associated with the assumption of the role and self-conception of being elderly are negatively valued in American culture, and because there is no compensatory attribution of prestige in other societies, the first reaction of many older people is some kind of disengagement and depression. The disengagement is by no means completely voluntary. The older person is pushed [author's emphasis] out of his occupations, out of formal and informal associations connected with occupation, and even out of leadership roles in many kinds of non-occupational associations. It is a matter mainly of social fact, not so much of natural inevitability, that many Americans reaching the age of 65 shift into a social role of disengagement. (18, p. 72)

Emphasis is placed on the necessity of maintaining the older person in an engaged state to inhibit the deteriorating effects of age and increase life satisfaction. (16)

The interactionists see several trends (16) developing which

2 The activity theorists seem to interpret the term inevitable as desirable in the disengagement theory. This interpretation is considered somewhat unjustified in light of the theory's attempts to avoid value judgments. 
counteract the forces contributing to disengagement. The increasing health and vigor in more older persons resulting from technological advances in medicine and health care plus the tendency for people to retire from their main life roles at an earlier age will cause people to be less willing to disengage. Increasing financial security and availability of more and more engagement activities for older people also contribute to this trend.

Relative to these counteracting forces Rose (16, p. 20) underlines the significance of the development of the "aging group conscious"

As people become old in American society, some are able to maintain most of their roles as typical adults without any deprivations. A much larger number lose their adult roles by seeking to develop new ones, their lives can take one of two courses: Either they succeed in creating new independent roles, or they create new roles for themselves in an aging subsociety which is different from the general American one. The last-named are those who become "aging group conscious." In referring to them as "conscious" we do not mean that they are aware of all that is happening to them sociologically. We simply mean that they become conscious of a subsociety of the aging and develop some identification with it. There are obviously degrees of being aging group conscious. (16, p. 20)

Rose maintains that this group will actively seek solution to the problems of the elderly, will publicize their plight, and by virtue of their association and activity may raise the prestige and dignity of being old. Last he maintains that the accomplishment of this last factor alone will remove the main cause of disengagement.

In addition to the role the aging people themselves play in 
counteracting disengagement, the interactionists $(2,3)$ stress the importance of the rest of society playing an active role in making new roles and engagements available to older people.

... concentration of helping the aging person find new roles which do not depend on former occupation or life-role from which the aging person has retired. Requisite to the development of a new self-image is a culturally approved set of values respected by everyone which would reinforce the development of this new self-image; new roles through which the person may express his new image. The roles must be meaningful and bring the equivalent in respect he has lost. (3, p. 528-529)

\section{Disengagement as an Extension of a Life Pattern}

A number of theorists $(9,10)$ in aging reject both activity and disengagement as being adequate to express the process of aging. It is asserted that the amount and style of participation in an aging person are an extension of the patterns of participation exhibited in childhood and as young adults.

They (20) oppose the view that chronological age itself is a major determining factor in behavior. This view implies both that physiological changes associated with aging notably affect behavior potentials, and that role expectations related to age are consistent for all persons of a given age.

It is assumed that various kinds of social activities such as church, voluntary, civic, and political participation are learned and modifiable and for the most part, barring disabilities and senility, 
age limits only those activities requiring physical performance at maximum levels.

The most important factors limiting participation include the person's "life statuses" such as marriage, sex, and socio-economic status, Since these statuses are alterable, shifts in them would be expected to influence participation patterns.

The correlation between life cycle statuses and age is recognized but is qualified by suggesting that caution must be exercised in attempting to relate age to behavior variations. The mistake of correlating age with participation, for example, would leave out the important middle step, the effect of the life status role. It would be more correct to say that age and participation jointly relate to the major adult statuses which make up the life condition of the older person.

\section{Utility Theory of Aging}

As expressed by Hamlin (8) the utility theory concentrates on the reality and the why of the existence of aging. Questions posed include "who needs old people?" and "why do people need old age?" Conclusive answers are not attempted but certain concepts are noted for further exploration.

It is suggested that society needs old age in proportion to its cultural progress. The utility of old age becomes more apparent as 
a culture progresses from primary goals of securing food to automation. Age increases as culture progresses because there is more need for knowledge and wisdom than for strength.

The concept of need to develop programs to accommodate the aged is rejected by utility theorists, who do not see society as particularly charitable. Rather, utilitarians see programs developing in response to society's need. The assumption is that the life-span does not increase unless there is a specific need for an increased life-span. If need is expressed, programs for its profitable use will be developed. The general tone of the utilitarian is that if old age is a reality, it should and will be used profitably by society.

\section{Relating Theory to the Project}

The project members were able to use many of the concepts proposed by these four theories in constructing the guiding hypotheses. No one theory seemed totally correct either to adequately explain the aging process or what, if anything, to do about it. It is the feeling of the group that the findings of the study exhibit parts of each theory and further suggest interrelationships between the theories. 
CHAPTER II

\section{APPROACH}

The major objectives of this project were to explore with the aging person himself the alleged disengagement process and to secure his proposals and opinions, if any, on possible ways to reverse or modify it in the direction of more meaningful participation.

The research group was composed of three members, each possessing a professional interest in the problems of the aged. The project was intended to be exploratory and serve as a springboard to further Social Work research in the field of social gerontology.

A review of the literature was the first formal task of the research group. The purpose of reviewing the literature was to become better acquainted with existing knowledge and theories relating to the aging process and its effect upon the social, emotional, physical, and economic status of the aged.

A series of meetings were held with the Director of Northwest Tower prior to initiating the study. Acting as liaison to the project, the Director helped with the physical tasks of selecting and randomizing the sample, acquainting the group with the setting, and evaluating and defining variables. 
The hypotheses to be explored were as follows:

I. The older person experiences progressive disengagement from society which results in feelings of isolation, depression, frustration, and despair.

II. The aging person is dissatisfied with the degree of this process of social disengagement.

III. The aging person gains satisfaction by participating in activities which lead to individual growth and/or benefit others.

IV. The aging person does not have the capacity nor the desire to participate in many activities or to continue the fulltime roles of parent, job holder, and active citizen.

V. The aging person would like to choose his activities according to his desires and needs,

VI. The aging person will more likely participate in activities if he is able to obtain adequate health and medical care and has financial security.

The project's limited sample in terms of population, economic level, as well as the relative absence of similar housing structures in the area precluded any attempts to arrive at definitive conclusions. 


\section{THE SAMPLE}

The study was focused on elderly residents living in the hi-rise addition of Northwest Tower. Four major subdivisions were identified: unmarried females, unmarried males, and married males and females. These categories contained 96,15 , and 26 people respectively.

A systematic sample of the entire population of Northwest Tower was drawn from their files, beginning with a randomly selected number without replacement, stratified by marital status, with an equal number of cases in each category. Twelve cases were drawn from each category, resulting in a total sample of 48 . The number of interviews possible in the time available was the single most important factor in determining the size of the sample.

Care was taken to avoid distortions in the arrangement of names which might tend to bias the sample by prior removal of the names of residents who were physically ill, hospitalized, or vacationing.

Seven respondents of the sample refused to cooperate or were not physically accessible, necessitating a return to Northwest Tower to select alternate subjects. Additional names were needed to fill the void in two major categories, unmarried females and married couples, An alphabetical letter was randomly chosen for each 
interviewer from the roster of names. Using this letter as a starting point, every third single female was extracted from the file until the desired number of alternate subjects had been identified.

Each interviewer was assigned 12 subjects to interview, equally divided among the subgroupings. Three people outside of the thesis group assisted in the process of assigning the appropriate number of respondents to each of the interviewers. Twelve names were randomly selected from each subgrouping and assigned to each interviewer.

Two defects in design and planning were evident. First, the sample as a whole was too small to yield definitive conclusions or to lend itself to inferential analysis in some instances. Second, the need for alternate subjects was not taken into account. As noted above, this latter defect was corrected by drawing additional subjects.

\section{THE SCHEDULE}

An interview schedule was adopted as the primary method of testing the project's theoretical framework. The schedule was based upon itemized questions and concepts found in the literature as well as those formulated by the thesis group itself. The resulting interview schedule was structured and composed of a combination of specific and open-ended items in order to allow for a wide range of responses by the elderly. The information to be compiled was 
designed to be both qualitative and ordinal, for nonparametric analysis.

The interview schedule was conceived as the instrument for exploring the conceptual framework behind the study's guiding hypotheses. The initial portion contained items related to the subject's age, sex, income, membership in recreational clubs, and church affiliation.

In addition to face sheet information, items were designed to secure data in regard to the developmental history, from age 40 to 70, of the subject's participation in family, recreational, social, political, civic, and occupational interests and activities.

Several questions were formulated to explore factors relating to the disengagement process among the aged, such as isolation, depression, loneliness, frustration, and despair. The primary objective of these questions was to obtain information in regard to the nature, degree, and intensity of disengagement taking place as well as to get at some of the associated variables. Other items were designed to inquire into the aged person's hopes and aspirations, what he expected from old age, and the conditions which prevented him from doing what he most wanted to do, And last, the researchers wanted to secure each respondent's opinions and proposals for improving the conditions under which he lived. 


\section{PRETESTS AND TRAINING}

The first pretest was conducted in role play by the researchers as interviewer and interviewee in group meetings. This testing device pointed up areas of deficiency and led to further revision and interpretation of certain questions and the method of interviewing.

The second pretest was conducted at Iris Court, a low income housing project for the elderly. Three subjects from each subgroup were selected by random sample and equally divided among the interviewers. Each respondent was contacted prior to the interview situation to acquaint him with the project and its purpose.

Training strategies were discussed prior to conducting the study. The primary training device was the pretest and reaching consensus on meanings. The consensus was that a uniform method of collecting the data would insure valid recording and interpretation. Each interviewer was encouraged to use his own approach in attempting to establish rapport with the elderly. The interviewers were encouraged to be patient, understanding, and flexible while attempting to obtain information of a personal nature from the elderly.

Pretest experiences indicated general reliability in the interview schedule as a recording and interpretive instrument. Each item was discussed thoroughly and when two or more items were related to the same concept, they were cross-checked for response 
consistency. Several items were discarded because they proved to be either ambiguous or lacking in objective content, Other questions were modified to yield the information desired. Several items were altered to make the interview schedule more succinct and more understandable.

Since the pretest indicated a need for additional items to explore the older person's perception of his needs, desires, and relationship with the social structure, 17 new items were designed and included in the interview schedule. Of these items, five were related to the aged person's perception of the generation gap; three were concerned with present and desired responsibilities; and two questioned what place older people felt they occupied in the social structure. The remaining items invited the respondents to describe the ideal way in which older people should live and what factors prevented the ideal from becoming reality.

In the final analysis, the pretest indicated that developing and maintaining a warm relationship with the elderly person improved the quality as well as quantity of his responses.

\section{COLLECTION OF DATA}

The final interview schedule consisted of six pages and 57 items, 24 of which were open-ended questions designed to allow the respondent to express the full range of his feelings and opinions. 
A five point nominal scale was designed for the specific items (see Appendix for schedule).

A short news letter was drafted for a Northwest Tower publication to inform the residents about the study and to ask their cooperation. After the sample had been chosen, a brief cover letter was sent to each respondent giving a brief overview of the study and indicating a home visit or telephone call would be forthcoming in order to schedule an appointment. For those who did not have telephones, a home visit was made to set up an appointment or complete the interview the same day. All interviews were held in the home of the respondent.

An interview schedule rather than a questionnaire was administered to avoid the problems of poor eyesight, hearing loss, or any other physical handicap which might have prevented a respondent from participating in the study. The raw data were recorded by either checking the appropriate response to each item or, in the case of open-ended questions, by transcribing verbatim responses. The time required to administer the interview schedule ranged from one to two and one-half hours, depending on whether the respondent was married, in which case his spouse was also interviewed. There was evidence that the interview situation did not produce a significant amount of fatigue or boredom.

Of those respondents who chose not to participate in this study, 
the following reasons were recorded. Two subjects were unable to participate because of poor health. Another felt that motives for conducting the study were suspect. Others refused to cooperate at the point of contact. It was felt by the researchers that the discrepancy in chronological age between the interviewer and interviewees might have affected any given respondent's willingness or decision to cooperate. The outcome may also have been affected by individual differences in the interviewer's method of obtaining the data. In addition, the Director of Northwest Tower advised the researchers that certain residents were apprehensive about the study because they feared project members might be salesmen, solicitors, or possibly representatives from the housing authority. The proportion of elderly persons who either hesitated or refused to cooperate, however, was estimated to be less than 2 per cent.

The researchers were able to overcome some initial anxiety and resistance encountered at the beginning of several interview situations by conscious and sincere efforts to gain the elderly person's confidence and cooperation. Once the resistance had been overcome, all interviewers reported friendly relationships. Several of the respondents expressed a desire for a return visit by the researchers and interest in the results of the study. A copy of the research project will be made available for the residents of Northwest Tower when it is completed. 


\section{TABULATION}

Each interviewer tabulated and transcribed the information he had collected. The counting was done by hand, except for questions 8 through 11 which were tallied by machine.

The responses to questions 1 through 33, plus 57, were transcribed onto a tally sheet with properly labeled columns and rows. Each response was entered into the appropriate compartment of the tally sheet by means of a check. Individual totals were than transcribed onto a master tally sheet and cross checked.

Items 34 through 56, all open-ended questions, were discussed as to their type and amenability to classification. Because of the diversity in responses, these items were classified into categories and general headings by consensus to determine the direction of the data as well as its numerical value. The resulting information was compiled and transcribed onto the master tally sheet and cross checked by each individual coder.

\section{ANALYSIS}

Analysis of the data took three principle forms: descriptive statistics, chi square, and indices.

Descriptive statistics included the use of frequency distributions, percentages, means, medians, indices and range. 
Chi square was utilized as the method of determining whether the differences in response to items 14 through 33, plus 57, were due to random differences associated with the smallness of the sample or .whether statistical association was present. In a number of cases it was easier to approach the research hypothesis through its null form and test it by using chi square. The null hypotheses are outlined and discussed in the final chapter.

To measure the extent of disengagement in items 8 through 11 which were concerned with the life areas of family, occupation, recreation, civic-political, hobby, and religion, an index of movement was adopted:

$$
\mathrm{M}=\frac{100 \overline{\mathrm{x}}_{1}-\overline{\mathrm{x}}_{2}}{\overline{\mathrm{x}}_{1}-5}
$$

As defined, $\bar{X}_{1}$ represented the mean age of group $40-50, \bar{X}_{2}$ the mean age of group 60-70 and 5 designated the upper limit of possible movement on the scale. Percentage form was accomplished through multiplying by 100 . This index measured the degree of movement that actually occurred proportionate to the amount which was possible within each of the age ranges.

A second index was designed to measure the potential for frus tration by determining the satisfaction level of the respondents.

The frustration index used seven schedule items as indices of satisfaction. Responses to items 19 and 20, which had to do with the 
amount of time to self available and the amount needed, were tabulated. The same procedure was followed for responses to items 35 and 36, having to do with present and desired responsibilities. Concordant answers in each were awarded a score of 1 . Discordant answers received 0 . The remaining three items, 39, 47, and 55 meas ured the respondent's desire for change in his present life situation. If no desire for change was expressed, the item received a value of 1. The maximum possible score was 5 , the minimum 0 . A score of 2 or less indicated dissatisfaction and a desire for change, 3 was designated as a neutral area, and 4 or more indicated satisfaction.

It was determined that if dissatisfaction and desire for change were present, frustration might result if change were blocked. Items 37,41 , and 55 were concerned with the factors which prevented the respondents from making desired changes.

In summary, to arrive at a measure of frustration various indices of desire were classified on a nominal scale. These in turn were related to factors which in some degree prevented the achievement of these desires. The amount of frustration was thus dependent upon the amount of desire as a cross classification of the amount of blocking, as seen by the respondent.

An important aspect of the methodology as a whole was the conscious feedback and interaction of the members of the study group from conceptualization through preparation of the report. 


\section{CHAPTER III}

\section{FINDINGS AND IMPLICATIONS}

This chapter will review the findings and their implications, discuss the limitations of the project, and suggest areas in which further research is needed.

\section{FINDINGS}

The schedule contained seven items designed to provide the general description of the respondents which can be found in Chapter I. For purposes of clarity and continuity the data obtained from the remaining items which contributed to the development of the descriptive and inferential findings will be handled together and grouped according to the six hypotheses.

Because of the small size of the sample, it was considered necessary to determine whether the distribution of responses in items 14 through 33, relating to the potential consequences of disengagement, were random accidents due to the sample size or whether the project was justified in saying they were associated with the consequence, such as loneliness, depression, or isolation, being examined. 
Chi square was used to test the null hypothesis:

There is no significant difference between the distribution of

responses for items 14 through 33 and that which would be expected

to occur by chance.

If accepted the distribution of responses to the items must be con-

sidered not associated to the consequence being examined but related to chance. Table I lists the results.

TABLE I

SUMMARY OF TESTS OF SIGNIFICANCE BETWEEN ACTUAL RESPONSE DISTRIBUTION AND THEORETICAL RESPONSE DISTRIBUTION AT .05 LEVEL

\begin{tabular}{|c|c|c|c|c|}
\hline & Question & $\begin{array}{c}\text { Degrees of } \\
\text { Freedom } \\
\end{array}$ & $\begin{array}{c}\text { Chi } \\
\text { Squares }\end{array}$ & $\begin{array}{c}\text { Test } \\
\text { Result }\end{array}$ \\
\hline 14 & Isolation & 4 & 12.83 & $s^{1}$ \\
\hline 15 & Depression & 4 & 25.96 & $\mathrm{~S}_{2}$ \\
\hline 16 & Depression & - & $-\cdots$ & - \\
\hline 17 & Depression & 4 & 25.34 & $S$ \\
\hline 18 & Depression & - & ---- & - \\
\hline 19 & Isolation & - & $-\cdots$ & - \\
\hline 20 & Isolation & 4 & 14.49 & $S$ \\
\hline 22 & Isolation & 4 & 16.14 & $\mathrm{~S}_{3}$ \\
\hline 23 & Isolation & 4 & 8.46 & $\mathrm{NS}^{\mathrm{J}}$ \\
\hline 24 & Isolation & 4 & 30.12 & $\mathrm{~S}$ \\
\hline 25 & Isolation & 4 & 5.95 & NS \\
\hline 26 & Isolation & 4 & 26.35 & $S$ \\
\hline 27 & Isolation & 4 & 9.72 & $S$ \\
\hline 28 & Isolation & 4 & 13.02 & $S$ \\
\hline 29 & Participation & 4 & 17.60 & $\mathrm{~S}$ \\
\hline 30 & Participation & 4 & 8.04 & NS \\
\hline 31 & Participation & 4 & 3.27 & NS \\
\hline 32 & Participation & - & ---- & - \\
\hline 33 & Participation & - & ---- & - \\
\hline
\end{tabular}


With respect to the remaining hypotheses, group members were specifically interested in determining whether disengagement existed, whether or not it presented a problem to the older people, and if so, to ask what should be done.

Six research hypotheses were constructed, and where appropriate information for testing was available, they were converted into null hypotheses to facilitate the use of inferential testing in addition to descriptive analysis.

The six research hypotheses hereafter referred to by number were;

I. The older person experiences progressive disengagement from society which results in feelings of isolation, depression, frustration, and despair;

II. The aging person is dissatisfied with the degree of this process of social disengagement;

III. The aging person gains satisfaction by participating in activities which lead to individual growth and/or benefit others;

IV. The aging person does not have the capacity or the desire to participate in many activities or the full-time roles of parent, employee, and active citizen;

V. The aging person would like to choose his activities according to his desires and needs; and

VI. The aging person will more likely participate in activities if he is able to obtain adequate health care and has financial security. 
$\underline{\text { Disengagement }}$

The index measuring the movement toward more or less activity in six different areas of the respondent's life indicates in percentages the amount of movement which occurred relative to the maximum amount of movement which was possible.

Table II shows the results of the application of the index.

TABLE II

PERCENTAGE OF MOVEMENT TOWARD MORE OR LESS ACTIVITY IN 48 PEOPLE AGES 40 TO 70 AND 13 AGES 40 TO (72-88)

\begin{tabular}{lcc}
\hline Life Areas & $40-70$ & $\begin{array}{c}40-(72-88) \\
\mathrm{N}=13\end{array}$ \\
\hline & $\mathrm{N}=48$ & $85 \%$ less activity \\
Recreation & $19 \%$ less activity & $97 \%$ less activity \\
Occupation & $28 \%$ less activity & $61 \%$ les activity \\
Family & $25 \%$ less activity & $27 \%$ less activity \\
Civic-Political & $5 \%$ less activity & $7 \%$ less activity \\
Religion & no movement & $21 \%$ more activity \\
Hobby & $7 \%$ more activity & \\
\hline
\end{tabular}

As applied to this group of older people, results of the index verified the feelings of the project members that increased disengagement would be apparent in the recreation, occupation, and family life areas of the respondents and increased engagement in the hobby life area. Unsupported, however, was the impression that respondents would increase activity in the civic-political and religion life areas.

Movement in the 40-(72-88) group is based on data obtained in 
the interviews of one group member, The three not included in the 40-(72-88) bracket were still in their sixties. A marked decrease in activity was noted in this older age group as compared to data obtained when they were younger in five of the life areas. Hobby activities, however, increased.

\section{Isolation}

Comparison of respondents' present activity and activity between the ages of 30-50 in three different areas was used to determine if the tendency toward isolation was present, Tabulation showed that 64 per cent of the older respondents presently spent less or much less time seeing and doing things with other people; 70 per cent spent more or much more time thinking about people and events in the past, and 73 per cent spent more or much more time in essentially individual activities including reading, listening to the radio, and watching $\mathrm{T} . \mathrm{V}$.

It was felt that isolation would also be shown if the respondents indicated feelings of loneliness. Only nine people indicated they ever felt very lonely. Of these nine, however, five were unmarried females. The majority of respondents indicated little or very little loneliness, The typical kind of response was 'I don't allow myself to feel lonely." 
$\underline{\text { Depression }}$

Items regarding depression met essentially the same reaction. The most frequent responses were in the lower categories of little or very little depression. Of those six who did reveal frequent and severe depression, however, four were unmarried females. A marked majority indicated infrequent and not very severe depressions, Eighty-five per cent of the time the respondents classed themselves in good or in very good spirits. The others fell in the so-so category.

$\underline{\text { Frustration }}$

The results of the index used to measure the respondent's satisfaction with his present life situation are shown in Table III.

TABLE III

SATISFACTION SCORE DISTRIBUTION

\begin{tabular}{ccc}
\hline Score & Frequency & $\%$ \\
\hline 0 & 5 & 10 \\
1 & 20 & 42 \\
2 & 10 & 21 \\
3 & 8 & 17 \\
4 & 2 & 6 \\
5 & 3 & 100 \\
& $\frac{3}{48}$ & \\
\hline
\end{tabular}


A score of 2 or less was considered to represent dissatisfaction with present circumstances by indicating a desire for change. A score of 3 indicated a balance of satisfaction and dissatisfaction in relevant areas of the person's life. Four or more indicated satis faction with present circumstances. Seventy-three per cent of the respondents scored 2 or less.

The project members reasoned that if respondents were prevented from making desired changes, dissatisfaction would become frustration. Follow-up questions indicated that age, health, and lack of money combined were cited 80 per cent of the time; and transportation, lack of jobs for older people, and fear combined were cited 20 per cent of the time as factors blocking change.

\section{Despair}

The item designed to test the presence of despair disclosed that 86 per cent of the respondents considered their chances for getting the things they would like to have as hopeless or very hopeless. Of the remaining seven respondents, two were moderately hopeful, two were hopeful, and one was very hopeful. Two others were unable or unwilling to answer.

Research hypothesis I, relating to the presence of progressive disengagement and its consequences, was accepted with some important reservations. 
Some disengagement was found but its progressive effect was limited in the 40-70 age group. Most disengagement appeared to occur in the mid-seventies and beyond. Results were inconclusive, however, because of the small population.

The assumption that isolation, frustration, and despair would be found was supported. However, the amount, degree, and severity of each were not determined. The older people rejected any feelings of depression.

Dissatisfaction with Degree of Disengagement

Research hypothesis II was approached through the null hypothesis:

There is no significant difference between the kind of activities presently available which were most enjoyed and the kinds of activities respondents would plan for themselves with respect to their individual and social nature.

$$
\mathrm{Chi}^{2}=23.76, \quad \text { d.f. }=2, \quad \mathrm{p}<.01
$$

The null hypothesis was rejected at the .01 level.

Sixty-five per cent of the activities the respondents stated they presently enjoyed most were those activities they could perform alone. Reading, writing, resting, and relaxing were most often mentioned.

In contrast, 73 per cent of those activities respondents would 
plan for themselves required the participation and companionship of others. Included were theatre groups, pot luck dinners, bus trips to interest areas, and book review clubs. Further examination of these activities revealed that 65 per cent of them were not presently included in the program at Northwest Tower.

Though there were individual differences in the various responses of the older people, the results of the test of the null hypothesis seemed to show that respondents enjoyed some activities which they could perform by themselves and some activities which they could do with others. The relationship to research hypothesis II is shown in their desire to reverse the present $65 / 35$ percentage ratio of disengagement/engagement to a $27 / 73$ ratio.

The hypothesis that older people are dissatisfied with the degree of their disengagement was accepted.

Attainment of Satisfaction

It was posible to approach research hypothesis III with the null hypothesis:

There is no significant difference between the activity program available at Northwest Tower and the activity program respondents would plan for themselves with respect to the entertainment or benefit dividends of each.

$$
\mathrm{Chi}^{2}=25.4, \quad \text { d.f. }=2, \mathrm{p}<.01
$$


Activities most mentioned as available at Northwest Tower include birthday parties, bingo games, card playing, hobby shop, and Friday afternoon volunteer work. The majority, 79 per cent, were activities which were primarily designed to entertain the older person. The kinds of activities suggested by those people interviewed for this project many times included those already mentioned. Sixty per cent of the time, however, the kind of program the older people planned for themselves included things such as availability of a medical staff, opportunity for exercise in addition to walking, part-time work, entertainment programs in which the older person could participate, and educational opportunities. The latter program emphasized activities which benefited the older person or enabled him to help others.

The importance of research hypothesis III which suggests that older people gain satisfaction by participating in activities having personal and/or societal benefit is demonstrated by the respondent's desire for change from primarily entertainment activities to a program directed toward helping himself and/or others. The hypothesis was therefore accepted.

Desire for Many Activities

In order to present the findings regarding research hypothesis IV, it was necessary to separate it into two parts: IVa related to the 
older person's desire for many activities; and IVb relates to his desire and capacity to continue life-time responsibilities.

It was possible to test the respondent's desire for many activities on an inferential basis by approaching it with the null hypothesis:

There is no significant difference between the number of activities desired and the number of activities available with respect to the older person's participation at Northwest Tower.

$$
\mathrm{Chi}^{2}=16.52, \quad \text { d.f. }=4, \mathrm{p}<.01
$$

The null hypothesis was rejected at the .01 level.

A majority, 72 per cent, of the respondents indicated that there were many or very many activities available to them at Northwest Tower. Only 12 per cent indicated there were very few activities available.

The respondents expressed more variation in their desire for participation in activities. Forty-four per cent desired to participate in many or very many activities as opposed to an equal percentage of people desiring participation in few or very few activities. The remaining 12 per cent of the respondents selected the "some" category to describe their desire for participation.

The results of the test of the null hypothesis indicate the weakness in stating a general hypothesis that older people lack the desire for many activities. The results more clearly suggest that people 
retain individual needs and desires for activity even as they age.

Research hypothesis IVa was rejected. Since both the null hypothesis and its alternate were rejected, the area of the older person's desire for activities must be examined more thoroughly before drawing any definitive conclusions.

\section{Desire and Capacity to Continue Life-Time Responsibilities}

Research hypothesis IVb, relative to the capacity and desire of the aging person to continue the life-time responsibilities of parent, job-holder, and active citizen, is examined tabularly by contrasting present and desired responsibilities with the factors which prevent older people from desiring and/or accepting additional responsibilities. (Table IV and Table V) Table VI presents information regarding responsibilities from which some older people would like to withdraw and a summarization of their reasons.

TABLE IV

PRESENT RESPONSIBILITIES

\begin{tabular}{lrr}
\hline & Frequency & $\%$ \\
\hline $\mathrm{N}=48$ & & \\
Household $^{1}$ & 48 & 80 \\
Occupational $_{\text {Parental and Family }}$ & 2 & 3 \\
Civic & 6 & 10 \\
& 4 & 7 \\
\hline
\end{tabular}

${ }^{1}$ Includes none, self, spouse, home maintenance 
TABLE V

ADDITIONAL RESPONSIBILITIES DESIRED

\begin{tabular}{lcr}
\hline \hline & Frequency & $\%$ \\
\hline & & \\
& & \\
Occupational & 14 & 70 \\
Parental and Family & 1 & 5 \\
Civic & 5 & 25 \\
\hline
\end{tabular}

TABLE VI

RESPONSIBILITIES FROM WHICH OLDER PEOPLE WOULD LIKE TO WITHDRAW

\begin{tabular}{lcc}
\hline \hline $\mathrm{N}=4$ & Frequency & $\%$ \\
\hline Household & & \\
Occupational & 0 & 0 \\
Parental and Family & 1 & 20 \\
Civic & 1 & 20 \\
& 3 & 60 \\
\hline
\end{tabular}

Tables IV, V, and VI indicate the kinds of responsibilities each respondent presently has, the kinds he would like to assume, and the responsibilities from which he would like to withdraw. The kinds of reasons given by the four people who indicated a desire to withdraw from some present responsibilities were exclusively related to their uncertain health status and increasing age.

Table VII indicates that factors relating to the older person's 
capacity and/or lack of desire for additional responsibilities we re cited 90 per cent of the time as reasons for not assuming more responsibilities.

TABLE VII

FACTORS PREVENTING RESPONDENTS FROM ASSUMING ADDITIONAL RESPONSIBILITIES

\begin{tabular}{lcc}
\hline Factors & Frequency & $\%$ \\
\hline & & \\
& & \\
Lack of Desire & 23 & 45 \\
Negative Aspects of Aging & $23^{2}$ & 45 \\
Lack of Opportunity & $\frac{4}{50}$ & $\frac{10}{100}$ \\
\end{tabular}

${ }^{1}$ Includes loss of income, deterioration of health, and decreasing opportunities.

210 feared losing their ability to maintain their present responsibilities because of the negative aspects of aging.

All of the respondents desired to maintain personal responsibility for self and household. Less than one-third desired additional responsibilities such as parent, job-holder, and/or active citizen, and four who held these kinds of responsibilities desired to withdraw from them. The factors, mentioned by all 48 respondents, which prevented them from assuming additional responsibilities included lack of desire, negative aspects of aging, and/or lack of opportunity. Therefore, research hypothesis IVa relating to the older person's 
desire and capacity for responsibilities additional to self was accepted.

\section{Desire to Select Activities}

No additional items were included in the schedule to elicit specific information relative to research hypothesis V. Information derived from other sources, however, gives some insight into the aging person's wish to choose his activities according to his desires and needs.

The respondents tended to express little interest in joining programs of activities, even programs which would be specifically tailored to their interests.

The majority, 71 per cent, rejected offers of help to join activities and 67 per cent indicated such help would be of little value to them.

When asked to plan a program of activities for older people, the respondent tended to reply that he lacked awareness of others' needs and, therefore, was unwilling to plan for others. Further questioning usually elicited mention of a variety of activities. Included in 20 per cent of the responses was the reaction that, "Each older person should be able to do what he would like to do."

An additional 41 per cent of the responses concentrated on planning for the needs of the older person such as better medical 
care, cheaper and better transportation, adequate exercise, and more part-time jobs.

The results relative to research hypothesis $\mathrm{V}$ were indeterminate. Sufficient information was not elicited to make a definitive conclusion regarding the acceptance or rejection of this hypothesis.

Negative Aspects of Aging Which Inhibit Participation in Activities

Research hypothesis VI was approached tabularly by indicating the factors at work in the older person's life which decreased his ability to be active and maintain an ideal way of life.

The combining of two factors to make one category in Tables VIII and IX was suggested by the older person's own tendency to link them in his response and the interdependence they appear to share.

\section{TABLE VIII}

FACTORS PREVENTING IDEAL WAY OF LIFE

\begin{tabular}{lcc}
\hline \multicolumn{1}{c}{ Factors } & Frequency & $\%$ \\
\hline $\mathrm{N}=48$ & & \\
& 25 & 41 \\
Health and Age & 21 & 34 \\
Lack of Money and Transportation & 7 & 11 \\
Lack of Opportunity & $\frac{8}{61}$ & $\frac{13}{99}$ \\
Other & & \\
\hline
\end{tabular}

Table VIII relates to the way of life the respondent would consider to be ideal for him and lists those factors which prevent living 
that way. As in Table VII, the negative aspects of aging, health, age, lack of money and transportation are the prime preventive factors. The "Other" category contains responses which lacked consistency and had no discerned correlation with the other categories. Table IX lists the conditions which make it difficult for the respondent to remain active. Results again show that health, age, lack of money and transportation were most often, 64 per cent of the time, cited as reasons for the respondent's decreasing ability to remain active.

TABLE IX

CONDITIONS WHICH MAKE IT DIFFICULT TO PARTICIPATE IN ACTIVITIES

\begin{tabular}{lcc}
\hline \multicolumn{1}{c}{ Condition } & Frequency & $\%$ \\
\hline Health and Age & 17 & 27 \\
Lack of Money & 9 & 14 \\
Lack of Transportation & 15 & 23 \\
Lack of Opportunity & 2 & 3 \\
Lack of Self Confidence & 7 & 11 \\
Other & $\frac{14}{64}$ & $\frac{22}{100}$ \\
& & \\
\hline
\end{tabular}

Research hypothesis VI was accepted. Factors relating to poor health and/or lack of money, were cited over 70 per cent of the time, as being responsible for respondents' inability to live the way they would like to live and participate in desired activities. 
$\underline{\text { Society's Responsibility }}$

The final purpose of the project was to report the aging person's opinion of society's responsibility to him. Hypotheses were not designed relating to this element of the project, It was felt by the group members that reporting opinions rather than testing them was more appropriate. Table $\mathrm{X}$ indicates the direction those opinions took. The categories shown were designed to present the results more clearly and concisely because particular responses tended to show a natural grouping.

TABLE X

SOCIETY'S RESPONSIBILITY TO THE AGING

\begin{tabular}{lcr}
\hline \multicolumn{1}{c}{ Responsibility } & Frequency & $\%$ \\
\hline Social Intervention & 36 & 60 \\
Encourage Respect for the Aged & 11 & 18 \\
Aged Should Help Themselves & 2 & 3 \\
Other & $\frac{11}{90}$ & $\underline{18}$ \\
& & 99 \\
\hline
\end{tabular}

Social intervention, comprising 60 per cent of the responses, included reactions which stressed the importance of providing the aging person with better resources to fight the negative effects of the aging process. These resources, for which society was held responsible, included better health care, more opportunity for financial security, and better means of transportation. The "Other" 
category was reserved for those responses which showed no particular relationship to the other three groups or to one another.

Summary of the Hypotheses and Conclusions

Table $\mathrm{XI}$ is a summary table which lists the research hypotheses and the conclusion reached regarding their acceptance or rejection.

TABLE XI

RESEARCH HYPOTHESES AND CONCLUSIONS

Hypothesis

Conclusion

I. Disengagement and its consequences

Accepted in Part

II. Dissatisfaction with the degree of disengagement

Accepted

III. Participation in productive activities

Accepted

IV. Capacity and desire for participation

Accepted in Part

V. Choice of activities

Indeterminate

VI. Factors enabling participation in activities

Accepted

Based on the findings of this study, with its limitations, older people appeared to experience some progressive disengagement which resulted in some isolation, frustration, and despair. They 
rejected any feelings of depression. The respondents seemed to be dissatisfied with the degree of their disengagement from society and indicated that they would gain satisfaction from participating in activities which benefit self or society. The older person desired responsibility for himself and his household but for the most part rejected continuing full-time involvement in the roles of parent, jobholder and active citizen. The respondents retained individual desires regarding the number of activities in which they wished to participate. Participation in desired activities appeared to depend on the individual health and financial status of the older person.

\section{IMPLICATIONS}

In general, the findings of the study imply that the aging person is not necessarily dissatisfied with the process of disengagement. Having borne the major responsibilities of parent, job-holder, and active citizen for a large share of his life, rest and relaxation without responsibilities, other than those immediate to his household, hold some appeal.

In contrast the findings also indicate that a life full of rest, relaxation, and no responsibilities holds little more appeal than a life full of major responsibilities.

The findings imply that the older person makes his adjustment to aging by his disengagement from responsibility to others, outside 
his household, and from full-time activity. His adjustment does not include disengagement from full-time self-responsibility. Rejection of loneliness and depression and maintenance of good spirits are important parts of his responsibility to self. Conversely, that frustration and despair which are indicated in the findings appear to emerge only when the person finds himself blocked from carrying out his responsibility to self. They seem to be the expression of his fear that if the barrier remains, he will eventually be unable to maintain himself.

In order to maintain self-responsibility, the older person seems to need participation in activities which are not only enjoyable but which also contribute to self benefit. For example, maintenance of household and opportunities to continue to learn, to retain vigor, and to be able to experience new people, places, and things. Maintaining self-responsibility also seems to mean making some contribution to others less fortunate than oneself. Requisite to his ability to continue these activities and maintain self-responsibility, the older person appears to feel that it is society's responsibility to provide adequate health care and financial security for the elderly.

A major implication of this study is that the nature of the activity program presently available to the respondents in Northwest Tower contributes very little to their ability to maintain selfresponsibility and indirectly acts as a hindrance since offering these 
activities inhibits constructing a more appropriate program. The older person has only his own very limited resources, acting alone, for devising the necessary activities which will help him maintain self-responsibility.

It seems clear that those people responsible for designing programs for these elderly people will have to re-think the concepts under which they provide activities such as bingo and birthday parties and fail to include discussion groups and exercise instruction. The study further implies that society needs to invest some of its wealth in programs to help provide financial security to the aged, which in turn will reduce the problems of obtaining transportation and health care. Programs of this nature will destroy many of the barriers which now prevent some older people from maintaining selfresponsibility and which cause fear, frustration, and despair in others.

By failing to develop programs designed to encourage selfresponsibility, society succeeds in fostering dependency among the aged.

The difference in percentage of maximum possible movement toward disengagement in the family, occupation, and recreation life areas between the ages $40-(72-88)$ as compared to $40-70$ shown in Table II implies some important considerations.

For example, the study indicates that disengagement first 
appears in the 60's when many life roles are changing but does not markedly show its effect until the mid-seventies when it seems to have its greatest impact. The mid-seventies also expresses greater preoccupation with the deterioration of personal health. The findings imply a relationship between deteriorating health and disengagement with this age group since the incidence of both appears to be highest in the mid-seventies.

The review of the literature concerning disengagement among the elderly gave background and perspective to the research project. As the study proceeded, the findings began to show some relationship to certain concepts presented in each of the four major theories regarding disengagement among the aged.

Cumming and Henry (6) presented disengagement as a gradual but inevitable process related to the advance preparation of society and the older person for the older person's death. Correspondingly this study found progressive disengagement in the family, occupational, and recreational life areas of the respondents. However, while some desire for less involvement with others was indicated, there was a tendency to relate their inability to continue to be active in society to the negative aspects of aging such as poor health and lack of money.

The interactionists $(12,13,16)$ who support the intrinsic or activity theory of disengagement recognize the older person's 
tendency to disengage but maintain that the process must be reversed. They believe that continuing engagement contributes to the emotional and physical well-being of the older person by increasing his satisfaction with life and decreasing his susceptibility to the negative aspects of aging.

The study findings show that the respondents are dissatisfied with the degree of their disengagement and that they would like more engagement with others. They did not, however, seem to want to maintain the full-time engagement of their youth. There was some indication that a certain amount of disengagement was also necessary to their emotional and physical well-being.

Some relationship was shown between the findings of the study and the theory that disengagement is an extension of a life pattern. (9, 10) Though lumping of the data, collected in the four categories of respondents, indicated the direction of the total response, examination shows variation was present among individual responses. For example, early withdrawal was apparent in some respondents. Others showed a slower decline in activity progressing over a longer period of time and still others apparently did not withdraw until later when there was a sudden and steep decline. As a whole, the findings indicate the presence of disengagement among the respondents. Examined individually, however, the findings suggest that individuals differ in their approach and response to the aging process. 
The utilitarian theory of aging (8) relates to the part of the study which examined the older person's desire for activities, specifically type and number. Utilitarians assume that the life-span does not increase unless there is a specific need for an increased life span. If the need is expressed, programs for its profitable use will be developed. Utilitarians also claim that if old age is a reality, it will be used profitably by society. The findings of the study indicate the reality of old age and suggest that the older person, by his expressed desire to help others, feels he has a contribution to make to society. The findings do not support the claim that old age will be used profitably by society, Present programs do not appear to be geared toward using what the older person has to give. Because of its request for this research project, however, it is felt that the Housing Authority is interested in developing programs which more closely respond to the mutual needs of older residents.

\section{CRITIQUE}

Preconceived ideas about disengagement and concentration by the project members on the possible damaging consequences of questions requiring self-examination relative to feelings about the effects of old age, hindered designing an effective schedule,

Results of the pre-test underscored the need for constructing questions using direct and uncomplicated terms, condensing some 
items, and eliminating others. For example, the phrase "increasingly separated" was revised to "lonely." Separate items which asked "How active do you want to be?" and "How much would you like to participate in activities?" were condensed to ask "In how many activities would you like to participate?" The item "In general how do you feel about this amount of separation?" was omitted entirely from the final schedule.

Despite these changes, which considerably improved the schedule's effectiveness, tabulation of the results of the final schedule indicated additional revisions were needed. For example, three items brought so little response that each failed to collect enough information for adequate analysis. Overall appraisal of the data indicated they were superfluous to the purpose of the project. In addition, some information was lost because semantic differences among the interviewers resulted in the misinterpretation of one item. Information elicited by the item could not be tallied accurately and analysis was impossible.

Through repeated pre-testing these errors could have been caught and corrected. Because of the demands of other graduate course work in addition to the research sequence and the limited time alloted for completion of the project, however, pre-test repetition was not feasible.

Since the project was exploratory in nature, the questions 
were designed by the project members and were directly related to the guiding hypotheses. The utility of the schedule was enhanced by the orderly sequence of its questions.

It is felt that this orderly sequence, the thoughtful positioning of schedule items, and the emphasis each group member placed on taking the time to establish rapport with the respondent, in most cases encouraged honest, thorough evaluation and discouraged emotional anxiety.

In general, communication among group members during the interview period was good. In a few instances, however, project members failed to transmit information which would have increased the value of certain schedule items. For example, only one of the interviewers included the age category "now" in the items related to progressive disengagement from various activities. Since the majority of the respondents were over 70 , the information obtained by these items would have been much more relevant had all the group members added this fourth age category to the six schedule items.

Nevertheless, the project members found the design of questions 8 through 13 particularly useful in obtaining a maximum amount of information about the possibilities of progressive disengagement in a minimum amount of space and time.

Efforts, suggested by interviewing experience in the pre-test, were made to make the schedule as short and concise as possible so 
that the length of the interview would not discourage participation. In general $1 \mathrm{c}$ was possible to design one or two items which wouid do the work of many. For example, the charts which were developed to show the possible decrease in activity as people grew older, eliminated repetitious questioning. In some instances, however, needed information was lost by this condensation. For example, if items relative to desired responsibilities and activities had distinguished between part-time and full-time participation and questioned preventive factors operating in each case, the data would have been much more relevant to the hypotheses under consideration.

The findings suggest that older people desired some disengagement and some disengagement was found. The project does not adequately study the person's reaction to the disengagement which occurred to see if it correlated with the amount which was desired or if it were more or less. If these relationships were known, a more adequate study of the aging person's response to disengagement could be made.

It is felt that items relating to the hypotheses regarding activities were valuable in pointing out the discrepancy between available and desired types of activities.

It was not possible to use the information obtained by items 48 through 54, relating to the older person's place in society today and the existence of a generation gap, because of a lack of relationship 
to the research hypotheses. The data, however, would be useful to a future research study designed to examine the effects of one generation on the other in terms of the aging process.

The project studied only 48 people, evenly divided among four different groups. There were 12 each unmarried males and females and 12 married couples. At times this number was insufficient for adequate cell distribution and prevented tests of significance by subcategories. For the most part the number of people in each category was considered insufficient to predict trends or compare responses.

Finally, the project studied only those people who represented the particular segment of the aging population who are able to leave their homes and relocate in an apartment-type situation; who have sufficiently low incomes to qualify for public housing; and who were healthy enough to take part in the interview. The study does not represent aged people who are isolated, in need of protective services, institutionalized; or those older people who belong to middle or high income groups, live in private residences, or become active in community senior citizen groups.

\section{SUGGESTIONS FOR FURTHER RESEARCH}

The relatively homogeneous nature of the sample population in terms of residence, economic, social, and health status suggests 
that future studies might compare findings with other samples with different characteristics. For example, people who own and maintain their own homes, have relatively comfortable incomes, and belong to social organizations; or people in poor health, institutionalized, and in need of protective services. Would the findings of studies on different populations conform to or conflict with the findings of this project? Because of the ages of the sample population this same question would apply to a study of a different age group sample, such as the 60-70 age bracket.

If a similar study could be done over a larger population sample, it might be possible to see significant differences relating to the type and degree of disengagement between men and women, married and unmarried. Unmarried females tended to show more loneliness, higher frequency and greater severity of depression. Would a larger sample verify this tendency and indicate trends in other areas?

A further study might design a more thorough and analytical comparison of controlled as opposed to compulsory engagement and disengagement with respect to the satisfaction the aging person expressed with his life situation. Additional research might suggest that those people who could control their disengagement in terms of amount and kind would be more satisfied with their life situation than those who, for reasons beyond their control, were force to engage or disengage regardless of their needs or desires. 
Findings of the project indicate that as increasing numbers of people move into retirement, more research is necessary in order to plan programs more relevant to the needs of older people. The findings also suggest that an important part of increasing the program's relevancy is recognition of the older person's capability of serving as well as his need for service. 


\section{BIBLIOGRAPHY}

1. Boehm, Werner W. The plan for the social work curriculum study. Council of Social Work Education, August, 1956, Document 6-70-12. $103 \mathrm{p}$.

2. Cain, Leonard D., Jr. Aging and the character of our times. The Gerontologist. 8(4):250-258. Winter, 1968.

3. Cavan, Ruth Shonle, Self and role in adjustment during old age. In: Human behavior and social processes, ed. by Arnold M. Rose, Boston, Houghton Mifflin Company, 1962, p. 526-536.

4. Coleman, James C. Abnormal psychology and modern life. 3d ed, , Chicago, Scott Foresman and Company, 1964. XI$657 \mathrm{p}$.

5. Cumming, Elaine. Further thoughts on the theory of disengagement. UNESCO International Social Science Journal. 15:377393. 1963.

6. Cumming, Elaine and William E. Henry. Growing old. New York, Basic Books, Inc., 1961. 293 p.

7. Durkheim, Emile. Suicide, Glencoe, Illinois, Free Press, 1951. 405 p.

8. Hamlin, Roy M. A utility theory of aging. The Gerontologist. 7:37-45. June, 1967 .

9. Havighurst, Robert J. Personality and patterns of aging. The Gerontologist. 8(1):20-23. Spring, 1968.

10. Henry, William E. The theory of intrinsic disengagement. In: Age with a future, ed. by P. From Hansen, Philadelphia, F. A. Davis and Company, 1963. p. 415-418, 
11. Kent, Donald P. Aging and government policy: outlook for progress in the 1960's. In: Aging and the economy, ed. by Harold Orbach and Clark Tibbetts, Ann Arbor, University of Michigan Press, 1963. p. 195-208.

12. Kramer, Elaine and Joyce Unger, A survey of need in a public housing project for the aged. The Gerontologist. 7:204-206. September, 1967.

13. Lipman, Aaron and Kenneth J. Smith. Functionality of disengagement in old age. Journal of Gerontology. 23:517-521. 1968.

14. Parsons, Talcott. Viewpoint: old age as consummatory phase. The Gerontologist. 3:53-54. June, 1963.

15. Reichard, Suzanne, Florine Livson and Paul G. Petersen. Aging and personality. New York, John Wiley and Sons, Inc., 1962. $237 \mathrm{p}$.

16. Rose, Arnold M. A current theoretical issue in social gerontology, In: Older people and their social world, ed. by Arnold M. Rose and Warren A. Petersen, Philadelphia, F, A. Davis and Company, 1965. p. 359-366.

17. Group consciousness among the aging. In: Older people and their social world, ed. by Arnold M. Rose and Warren A. Petersen, Philadelphia, F. A. Davis and Company, 1965. p. 19-36.

18. The subculture of the aging: a framework for research in social gerontology. In: Older people and their social world, ed. by Arnold M. Rose and Warren A. Petersen, Philadelphia, F. A. Davis and Company, 1965. p. 3-16.

19. Talmon, Yonina. Dimensions of disengagement: aging in co1lective settlements, Unpublished manuscript read at the International Gerontological Research Seminar, Markaryd, Sweden. August, 1963, (Cited in: Rose, Arnold M, and Warren A. Petersen, Older people and their social world. Philadelphia, F. A. Davis and Company, 1965, p. 365)

20. Videbeck, Richard and Alan B. Knox. Alternative participatory responses to aging. In: Older people and their social world, ed. by Arnold M. Rose and Warren A. Petersen, Philadelphia, F. A. Davis and Company, 1965. p. 37-48. 


\section{APPENDIX}




\section{APPENDIX}

1. How old are you to your nearest birthday?

2. Sex

3. Income

4. Marital Status

5. Do you have transportation for these things?

Church

Shopping

Medical Needs

Visit Friends

6. Do you belong to a church?

7. Do you belong to a recreation club?

8. Would you rate your recreational activities?

Very inactive inactive so-so active very active

40

50

60

9. Would you rate your occupational activities?

Very inactive inactive so-so active very active

40

50

60 
10. Would you rate your family activities?

Very inactive inactive so-so active very active

40

50

60

11. Would you rate your civic-political activities?

Very inactive inactive so-so active very active

40

50

60

12. Would you rate your hobby activities?

Very inactive inactive so-so active very active

40

50

60

13. Would you rate your religious activities?

Very inactive inactive so-so active very active

40

50

60

14. As you become older do you more often feel lonely?

Very little a little somewhat much very much

15. Because of this loneliness do you feel depressed?

Verylittle a little somewhat much very much

16. How often do you feel depressed?

Never not very often often very often all the time 
17. How severe is this depression?

Not very severe slightly severe somewhat severe severe very severe

18. In general how would you say you feel most of the time? Very poor spirits poor spirits so-so spirits good spirits very good spirits

19. How much time to yourself do you have now?

Very little a little some quite a bit very much

20. How much time to yourself do you feel you need?

Very little a little some quite a bit very much

21. Is it much less less average amount more much more than you have?

22. How does it compare with the amount of time you felt you needed at an earlier time of your life, i. e. 30-50?

Much less less average amount more much more

23. How much of your time do you spend watching T. V, , listening to the radio, reading newspapers and magazines?

Very little a little some quite a bit very much

24. How does this relate to the amount of time you spent in the se activities when you were between 30-50?

Much less less about the same more much more 
25. How much of your time do you spend thinking about people you have known and things that have happened to you in the past? Very little a little some quite a bit very much

26. How does this relate to the amount of time you spent in these activities when you were between 30-50?

Much less less about the same more much more

27. How much time do you spend seeing and doing things with other people?

Very little a little some quite a bit very much

28. How does this relate to the amount of time you spent in these activities when you were between 30-50?

Much less less about the same more much more

29. How many activities are available for you to attend?

Very few a few some many very many

30. In how many activities would you like to participate?

Very few a few some many very many

31. If a program of activities is made available to older persons, how much would you like to join them?

Very little little some much very much

32. How much do you need someone's help in getting to activities? Very little little some much very much 
33. How valuable would some help from someone be to join some activities?

Very little little some much very much

34. What type of help from someone would be most valuable?

35. In this time of your life what kinds of responsibilities do you have?

36. In this time of your life are there any kinds of responsibilities that you would like to have?

37. What keeps you from taking on these responsibilities?

38. What activities that you engage in now do you like the most?

39. If you could do what you would most like to do, what would you do?

40. Which of these things would give you the most satisfaction?

41. What is it that really keeps you from doing these things?

42. What change do you think society must make to make it better for older people?

43. Which is most important?

44. Which is also very important?

45. If you were to plan a program of activities for older adults, what activities would you include in it?

46. What conditions make it hard to get into activities?

47. What would be the ideal way in which older people should live?

48. What place do older people have in our society today? 
49. Do you think there is a division between older persons and the youth?

50. What kind of division is it?

51. What causes this division?

52. What are some of the things that could be done about this division?

53. What do you think you personally can contribute to younger people?

54. What should be done to make your contribution possible?

55. If there were no money limitation, what would you be doing now?

56. Aside from money, what keeps you from doing these things?

57. What do you think your chances are in the future of getting the things you would like to have?

Very hopeless hopeless moderately hopeful hopeful very hopeful 